\title{
Industrial cleaning with Qlean Water: a case study of printed circuit boards
}

\author{
Mattias Lindahl, Niclas Svensson, Bo Svensson and Erik Sundin
}

\section{Linköping University Post Print}

\section{Tweet}

N.B.: When citing this work, cite the original article.

Original Publication:

Mattias Lindahl, Niclas Svensson, Bo Svensson and Erik Sundin, Industrial cleaning with Qlean Water: a case study of printed circuit boards, 2013, Journal of Cleaner Production, (47), $19-25$.

http://dx.doi.org/10.1016/j.jclepro.2013.01.032

Copyright: Elsevier http://www.elsevier.com/

Postprint available at: Linköping University Electronic Press http://urn.kb.se/resolve?urn=urn:nbn:se:liu:diva- 88920 


\title{
Industrial Cleaning with Qlean Water \\ - A Case Study of Printed Circuit Boards
}

\author{
Mattias Lindahl ${ }^{a,}{ }^{,}$, Niclas Svensson $^{a}$, Bo H. Svensson ${ }^{b}$ \& Erik Sundin ${ }^{c}$ \\ a. Linköping University, Department of Management and Engineering, Division of \\ Environmental Technology and Management, Linköping, Sweden. \\ b. Linköping university, Department of Thematic Studies - Water and Environmental Studies, \\ Linköping, Sweden. \\ c. Linköping University, Department of Management and Engineering, Division of \\ Manufacturing Engineering, Linköping, Sweden. \\ * Corresponding author: +46-13-281108, Mattias.Lindahl@liu.se
}

\begin{abstract}
:
Many manufacturing companies are looking for ways to substitute environmentally problematic cleaning methods for surface treatments with more environmentally friendly ones. In this paper, one potential solution is described. The Qlean method, based on cleaning with highly pure water (in this paper defined as Qlean Water), is a novel cleaning method. This method, now utilized at one plant at a leading major international electronic company, has substituted previous chemical-based methods for cleaning printed circuit boards prior to lacquering. This paper presents, based on that company's primary data, a comparative study using environmental analysis and economic life cycle cost review between cleaning with Qlean Water and conventional cleaning. The focus is on the environmental and economic performance of the two alternatives. The conclusion is that Qlean Water offers both a significant economic and environmental cost reduction and a better product. This is the case even though all identified economic benefits derived from using Qlean Water, e.g. that the quality and technical lifetime have been extended for the printed circuit boards with the Qlean Water cleaning method, are not considered in the economic analysis.
\end{abstract}

Keywords: Ultra-clean water, Ultra-pure water, De-gassed water, Life Cycle Assessment, Life Cycle Cost

\section{Introduction}

Many manufacturing companies are looking for ways to reduce their environmental impact (American Chemical Society, 2008; Sivakumar et al., 2009). One way is to reduce or substitute the use of chemicals, e.g. for cleaning. Industrial cleaning processes, often solvent-based and frequently a central part in the manufacturing process, are often considered to be problematic from an environmental perspective, since they involve various forms of more or less hazardous solvents and 
detergents (Sivakumar et al., 2009). The main concerns arise from: the manufacturing and transportation of those solvents and detergents; the energy consumption during their use, since the cleaning process often requires high temperatures; the potential risk of emissions to air, soil and water; and the resulting problematic hazardous waste that needs to be treated with special care. Therefore, reducing the consumption of chemical substances used in cleaning processes is important (Kikuchi et al., 2011).

In the electronic sector, cleaning of e.g. printed circuit boards (PCBs) is a central issue. Reasons for cleaning include removing oil, fingerprints, flux and dirt before coating, quality inspection and further treatment (Lindahl, 2010a; Sundin, 2004; Wendler et al., 2010). Finding new and more environmental friendly alternatives has been an issue for many years, as discussed e.g. by Nelson (1997). New alternative methods have been proposed, e.g. closed-loop systems (1997) with water being recirculated through a purification system and then reused to clean the printed circuit boards.

The objective of this paper is to present a novel method - the Qlean method (QM) and to analyze the economic and environmental pros and cons of the QM compared with conventional cleaning methods. The QM is based on cleaning with highly purified water (here defined as Qlean Water $(\mathrm{QW})$ ), which allows for cleaning/removing various forms of dirt without any additives. To illustrate the method the cleaning of (PCB) prior to lacquering is used as is the comparison above; a company substituted their old method with the QM.

\section{The Qlean Method}

Qlean Scandinavia AB has developed, as far as the researchers have been able to identify through an extensive literature review, a unique method to produce $\mathrm{QW}$ for use in their QM. When QW water comes into contact with dirt, it not only loosens e.g. algae and exhaust fumes, but also functions equally well on removing e.g. grease, oil, fingerprints and flux. The $\mathrm{QM}$ is used for cleaning e.g. building exteriors, large transformers, oil-contaminated stones, and hydroelectric dams, as well as industry components and PCBs before various forms of surface treatment.

The method for producing QW is based on a combination of various filter techniques. The "raw" material is often normal tap water, but with a few extra conventional filters even seawater and used water (recycling) can be used. In areas with scarce water resources, the latter can be a favorable option. For each volume of normal tap water used by the QW machine, the output of QW is approximately $60 \%$ leaving about $40 \%$ reject. The rejected water basically containing the matters detached from the $\mathrm{QW}$, can be used for other purposes such as irrigation or be treated in a regular water treatment plant. The more continuously the equipment produces $\mathrm{QW}$, the longer its components and filters work and the higher the QW quality it maintains.

When applying and using QW, the water's temperature is preferably around $4-10^{\circ} \mathrm{C}$, but higher temperatures also work. The important thing is that no heating is needed to get the desired cleaning effect. Depending on the object to be cleaned, several different techniques are used for applying the water, e.g. spray nozzles and traditional industrial dishwashers. Depending on what is cleaned, 
various types of filtering methods are used to purify the used QW so it can be either reused or used for other applications or returned to the natural environment.

One disadvantage with $\mathrm{QW}$ is that it cannot be stored for more than around 24 hours before it begins to lose its ability to clean oil and fat. The reason for this is that QW starts to absorb substances from its container or, if exposed to air, various types of gases. This implies higher conductivity (see Section 3.1). This means that the $Q M$ requires a semi-constant production of new, fresh QW. However, "dead" QW can easily be reprocessed and become QW again.

\section{Purity of Water Types}

From a scientific perspective, water refers to the chemical substance with the formula $\mathrm{H}_{2} \mathrm{O}$. However, in daily language the water concept is often used to describe $\mathrm{H}_{2} \mathrm{O}$ solutions (consisting of various mixtures of minerals, gases, etc.), for example those for drinking. Since this paper is about QW, it is of relevance to relate this "water" to some other types used, namely natural, deionized, distilled, ultra-pure / ultra-clean water and qlean water. Figure 1 provides a description of the degree of pureness of the "water" types described in this paper. Although there are standards for the classification of maximum contamination levels in highly purified water (see e.g. ISO 3696 (1987)), there are no accepted definitions for each type. As an example different actors term their water as ultra-pure, for example, even though the purity varies. Therefore, the different types of water in the figure described below represent a span on the degree of contamination scale.

- Natural Water - As the name indicates, natural water is water of varying quality found in nature, ranging from very dirty and polluted water to very pure drinking water, including water qualities like sea and lake water. This type of water normally contains various amounts of dissolved gases, ions, minerals, and organic and inorganic substances (Hach Company, 2002; Kemmer, 1988).

- Deionized Water - In deionized water, also known as demineralized water, mineral ions (salts) such as bromide, calcium, chloride, copper, iron and sodium are removed (Strathmann, 2001). The deionization does not remove the hydroxide or hydronium ions from water, since these are the products of the self-ionization of water to equilibrium. Furthermore, deionization does not significantly remove uncharged organic molecules, viruses or bacteria. Deionized water is created by taking clean natural water and exposing it to electrically-charged resins that attract and bind to the salts, removing them from the water (Kemmer, 1988). Because most of the impurities in water are mineral salts, deionized water often has a high purity similar to distilled water. It is possible to produce deionized water continuously and inexpensively using e.g. electrodeionization. Therefore, it is preferred over distilled water in many applications in chemical and biological laboratories as well as in industry. Deionized water is used in industrial applications to e.g. top-up lead acid batteries used in cars and trucks.

- Distilled Water - Distilled Water is produced by heating or boiling water in a special chamber that creates steam or gases, resulting in highly purified water. Thus,all inorganicand organic 
contaminants including heavy metals, ammonia, nitrate, chloride, industrial organic contaminants, and pollutants are removed (Kemmer, 1988). Ideally, distilled water should be nothing but $\mathrm{H}_{2} \mathrm{O}$, with a $\mathrm{pH}$ level of 7 and no additional gases, minerals or contaminants; in reality, however, this is not the case (Hach Company, 2002). It is more expensive to produce distilled water than deionized water, but the industrial application areas are similar. However, when the requirement on extra cleanness is required, distilled water (and sometimes double distilled water) is preferred (Hach Company, 2002).

- Ultra-Clean Water / Ultra-Pure Water - Ultra-Clean Water (UCW), or Ultra-Pure Water is produced by various combinations of filtering techniques in order to remove gases, salt, lime, minerals and metals from regular water, resulting in de-gassed and UCW (Karaman et al., 1996; Kemmer, 1988). However, there is no single definition for UCW, but it is often referred to as "deionized and filtered water" in many ways being similar to distilled water. Many industrial actors claim they are using UCW, but have different quality requirements for the water they need, which makes it hard to define UCW. Since the requirements may differ substantially one UCW may not work for another. Nevertheless, there are several characteristic requirements that are important to every end-user of UCW (Burkhart et al., 1997). These include detection in the UCW stream and control of: anionic contaminants, bacterial proliferation, metallic contaminants, organic contaminants and particulates (Osmonics Inc, 1997). Examples of laboratory-quality sources of UCW include Milli-Q, Elga Ultra, or Purite Neptune.

\subsection{Qlean Water Compared with Other Water Types}

Recent studies show the potential of de-gassed water to disperse hydrophobic dirt (Eastoe and Ellis, 2007; Francis et al., 2006; Francis and Pashley, 2006; Pashley et al., 2004). Those studies conclude that, through mechanical agitation of a hydrophobic surface with almost completely de-gassified water, the hydrophobic materials are dispersed in the water in a meta-stable emulsion for a sufficiently long period of time (Pashley et al., 2004). According to Pashley et al. (2004), this appears to be possible, since the natural cavitations, which would normally hinder a hydrophobic material from dispersing in water, are reduced. Furthermore, Pashley et al. (ibid.) note that there should be great potential for de-gassed water to be used instead of normal detergents. There are some references related to the use of ultra-clean and ultra-pure water in the electronics industry, specifically in the area of semi-conductor manufacturing (see e.g. Tadahiro (1995)). However, it remains unclear whether the water is used for cleaning or mainly for rinsing.

One way used for comparing QW and UCW is to analyze their conductivity $(\mathrm{S} / \mathrm{m}$ ) (or specific conductance), i.e. their ability to conduct electricity (Hach Company, 2002). Conductivity measurements are used routinely in many industrial and environmental applications as a fast, inexpensive and reliable way of measuring the ionic content in a solution, e.g. to monitor and continuously trend the performance of the water purification systems. In many cases, conductivity is linked directly to the total dissolved solids. Typical drinking water is in the range of $5-50 \mathrm{mS} / \mathrm{m}$, seawater is about $5 \mathrm{~S} / \mathrm{m}$ and UCW (high-quality deionized water) is about $5.5 \mu \mathrm{S} / \mathrm{m}$ at its lowest (Hach Company, 2002). QW has a conductivity of about 3-4 $\mu \mathrm{S} / \mathrm{m}$, not much lower than UCW, but its 
ability to clean oil and tar declines rapidly and disappears when the water conductivity increases to about $5 \mu \mathrm{S} / \mathrm{m}$.

\section{Method and description of the studied case}

\subsection{Research Methodology}

The development of the $\mathrm{QM}$, which implies cleaning with $\mathrm{QW}$, took place primarily at Qlean Scandinavia and was seen as a basis for this research. Personnel at Flextronics, the case company described in the following chapter, were interviewed and have provided extensive data for the environmental and economic calculations.

The environmental analysis presented in this paper is based on a simplified life cycle assessment approach (Hur et al., 2005). Greenhouse gas (GHG) emissions were calculated for a conventional cleaning technology using detergents, which were used prior to the introduction of the QM and compared to the QM. The resulting GHG emissions were calculated in SIMAPRO using GWP ${ }_{100}$, which is a life cycle assessment tool, and the generic data was derived from the Ecoinvent database (Frischknecht et al., 2007).

The analysis only studies the use phase of the processes i.e., the infrastructure needed for the processes is not included. Furthermore, due to the nature of the study it was not possible to get any data or further information on the detergent used in the conventional cleaning step. Since there are large amounts of different detergent chemicals for industrial cleaning, a decision was made that rather than using highly uncertain generic data, the manufacturing phases for the detergents would be omitted. A discussion on what these omissions might mean in terms of validity and generalization is presented. This is one reason why the study has not been expanded to investigate environmental impacts other than climate change. For example, the chemical characteristics are probably the most important factor for other impacts and will be discussed later in the article. An assumption about the transportation had to be made since the trace of the detergents stopped at a large chemical industry in the United States, and thus it was assumed that the detergents was shipped by boat from the United States to The Netherlands, and then by truck to Sweden. The energy use of the two alternatives during the cleaning cycle was measured during multiple cycles to ensure that the readings gave consistent results. Data for an average Swedish electricity mix was used for both alternatives, and the data for deionized water was taken from the Ecoinvent database, although adjusted to Swedish conditions by changing the electricity mix (Althaus et al., 2007; Frischknecht et al., 2007).

Another important issue to consider regarding the environmental performance was the indirect benefits from cleaning with $\mathrm{QW}$, such as the decreased amount of discarded PCBs. To be able to show these environmental impacts, data for a generic PCB was used (Hischier et al., 2007). Due to the huge differences in components on different PCBs, these results should be seen as indicative of the order of magnitude of greenhouse gas emissions saved by decreasing discarded PCBs, rather than as a detailed performance result. 
Life cycle cost analysis (LCC) is a methodology that is increasingly used to compare different alternative methods / products / services, i.e. to describe the life cycle cost / total cost of a given method / product / service. In LCC, the total expenses are added up, e.g. costs for the manufacture, transport, use and waste management (Swarr et al., 2011).

In order to compare various alternative methods / products / services with each other, a functional unit is defined as a unit that clearly outlines the primary functions of the methods / products / services offering. The functional unit then acts as a reference unit to which one can relate the input and output data. Therefore, the functional unit needs to be clearly defined and measurable. The quantity of materials or products needed to meet the defined function needs to be quantified and be the key unit of analysis.

The major components of LCC calculations are: energy and other consumable costs during the use phase; investment costs; and maintenance and service costs. In the calculations, it is important to note that many of the costs vary over time, and it is often quite difficult to predict how large the variations will be. For a simple calculation, the cost of electricity and maintenance is assumed to be equal within and between years. The energy and maintenance costs during the life of the product are calculated in today's money by using the so-called present value factor. Next, all of the costs are compared with each other (Swarr et al., 2011).

The LCC analysis is mainly based on data obtained from Flextronics AB (Flextronics, 2012) and Qlean Scandinavia $A B$ (Qlean Scandinavia $A B, 2012$ ). In the $L C C$, the unit of analysis was a fully-loaded washing machine with PCBs. Energy calculations were performed by researchers from Linköping University, Sweden. The LCC analysis does not include the investment cost for PCB washing machines, since the washing machines at Flextronics in Karlskrona use the same PCB for both the conventional chemical-based cleaning technology and the method using QW. Thus, equipment-wise there is no difference and therefore assumed to not affect the result.

\subsection{Industrial Case: Cleaning of Printed Circuit Boards}

In order to explore the potential of using QW for cleaning PCBs before lacquering, a case study was conducted at Flextronics International, a manufacturer of such boards (Sundin et al., 2009). The company manufactures PCBs on behalf of various other companies. When all the electronic components are mounted a protective varnish is sometimes required, due to the working conditions in which PCBs are used (Sundin et al., 2008). Previously, the company had used conventional cleaning of $\mathrm{PCBs}$ before lacquering.

The cleaning of the PCBs involve two major targets: fingerprints and flux stuck on the components from previous manufacturing steps. A quality issue with the conventional detergent cleaning method was that the detergent could get stuck in cavities due the structure of the components (see Figure 2). The hidden detergents could then, in a later stage of manufacturing and/or during use, leak out and damage the PCB and/or other components (Sundin et al., 2008). Furthermore, the detergent-based method sometimes resulted in that the text on the components was damaged during the cleaning process. 
During 2008 a test equipment for cleaning PCBs with QW was installed and integrated with the existing conventional washing equipment, as shown in Figure 3 (Sundin et al., 2009). This test equipment operated as the first demonstrator for using QW in cleaning PCBs. Following the first test results, permanent equipment was installed in 2009. The washing machines at Flextronics have a cleaning cycle consisting of three main steps, cleaning, rinsing and drying. The conventional washing technique used at Flextronics, prior to the use of QW, first washed the PCBs with detergents at a temperature of $65^{\circ} \mathrm{C}$ followed by rinsing seven times with deionized water (Table 1). The cleaning cycle was concluded with a drying step. The new washing method based on QW uses the old washing machines and the cleaning cycle includes the same drying step as the conventional washing technique. For the conventional cleaning method, the container with the detergent was emptied after 100 cleaning cycles. This dirty detergent solution was treated as a hazardous waste and transported to an incineration plant for destruction, while the QW from the cleaning is discharged into the normal water sewage system at the plant.

An additional positive environmentally-related effect by cleaning with $Q W$ is that the new method has resulted in a reduction of discarded components caused by the cleaning process. This is positive from an environmental point of view, since it implies less discarded products later on in the manufacturing process. Today, all PCBs requiring lacquering at Flextronics' plant in Ronneby are cleaned with QW.

\section{Results and Discussion}

\subsection{Environmental Implications of Cleaning with Qlean Water}

Comparisons between the two alternative methods show some substantial differences. The use of chemicals has been eliminated in the cleaning of PCBs with QW only. This leads to a number of positive environmental improvements. The working environment for the employees has been improved due to the reduction in the handling and transportation of chemicals in the manufacturing facility. In addition, reduced amounts of hazardous waste are created when no chemicals are used in the cleaning process. The use of QW has also eliminated the need for transport and treatment of hazardous waste from the cleaning facilities (Svensson, 2010). Since QW cleans at room temperature, the energy used during the cleaning cycles is reduced compared to the conventional method that cleans at a temperature of $60^{\circ} \mathrm{C}$. This implies less energy consumption related to heating and ventilation (to get rid of steam and hot air).

In addition, the washing time was reduced from 8 to 2 minutes and the rinsing sequence from 7 to 5 cycles. The environmental gains from this are offset somewhat by the use of electricity to produce the QW. All in all, the amount of electricity used in the cleaning process using QW was reduced by $30 \%$. All of the chemicals have been removed from the cleaning process; this means that all the manufacturing and thus transportation of the chemicals is avoided (i.e. manufacturing of chemicals is not included in the analysis as seen in Section 4.1).

In regions with a limited fresh water supply, water use can have a very important environmental impact. In the Flextronics case, the direct water use is higher for the QW method than when using 
detergents. However, since the fresh water supply resources in Sweden are still at a high level, no measures have been taken to optimize the water use in this case. In another application at a geographical site with a fresh water supply problem, other measures would probably have to be introduced. These measures could for instance be the introduction of waste water recycling equipment, which would make it possible to recycle the QW to some degree; this would probably be possible for the rinsing water from the conventional cleaning as well. As mentioned previously the QW method also works for seawater, although that would increase the maintenance cost and material use of the equipment which would lead to a decrease in environmental performance. However, the water use should also be seen from a life cycle perspective, and the higher use of electricity and transportation, as well as the manufacturing of the detergents and the printed circuit boards, will also cause direct and indirect water use, although at other geographical locations. Water use for the manufacturing of the PCBs before the final mounting of components can for instance range between 100 liters up to several thousands of liters per square meter of PCB (Environwise, 2006).

The environmental performance in direct GHG emissions of the two cleaning methods is illustrated in Figure 4a. The major differences in impacts are from electricity use for heating the water in the conventional cleaning alternatives and for the manufacturing of the QW. Furthermore, the amount of water used in the deionized rinsing steps seems to have quite a substantial impact. However, this contribution is harder to assess due to the way the electricity measurements were done. When measuring the electricity use for the conventional alternative the deionizing steps were outside the measured system, whereas for QW the manufacturing of the QW was measured. This means that the latter's electricity use is hidden together with the electricity use of the cleaning equipment. The results also suggest that the transportation of the detergents is minor compared to other processes. It is also interesting to note that GHG emissions from the manufacturing of the detergents as well as the filtering equipment for QW are missing. It is hard to speculate how much this omission would influence the results, but since the detergents are reused for a large number of cleaning cycles, and since the filter equipment has a very low maintenance requirement compared to output, these emissions are believed to be minor. However, the detergent might have other impacts not related to climate change, which is an important issue to remember. On the other hand, the environmental profile of detergents varies substantially, and some detergents have very minor environmental issues. In terms of generalizability, it could probably be assumed that electricity use through the use of heated water is a major impact for most cleaning equipment using detergents as surfactants, which means that could be seen as a major improvement potential for QW.

As mentioned in under 4.2 above, one of the major QW advantages noticed by Flextronics is that the number of discarded PCBs in the manufacturing process has decreased significantly. There are indications that the negative environmental impact avoided by this quality improvement is by far the most important environmental achievement of the use of QW in the Flextronics case (Figure $4 \mathrm{~b}$ ). The results should be seen as indicative of this indirect increase in environmental performance, since the data used for calculation of the PCBs was from generic LCA databases. However, even with general data the results clearly show that one of the largest improvements with regards to decreasing GHG emissions from the cleaning processes at Flextronics comes from improvement of quality in the lacquering process, due to less contamination remaining on the boards. 
Although the environmental impacts of the QW equipment have not been studied in detail, some conclusions on their importance can be made assuming that 11,650 batches of PCBs have been produced each year. The total weight of the equipment is around $100 \mathrm{~kg}$ and is assumed to be made of stainless steel. Another important factor is parts which need to be exchanged during operation; one such part is the particle filter, which loses its activated carbon. An assumption is made that $40 \mathrm{~kg}$ of activated carbon is used per year. Furthermore, the filters in the equipment can be assumed to have an impact since they are highly advanced technology. Here, it is very hard to assess the environmental impact of manufacturing; to get some hint; however, an assumption is made that half the price of the filters is made up of energy costs. Using this rather crude estimation, an approximate energy use in the manufacturing of the filters is $10 \mathrm{MWh}$ per filter. If a worst-case lifetime of 3 years is used to allocate these environmental impacts from equipment, the total emissions of climate gases increase with less than $2 \%$ in the case where indirect benefits from less discarded PCBs are accounted for.

\section{Economic Implications of Cleaning with Qlean Water}

The LCC analysis (Lindahl, 2010b) shows that the main costs that influence the LCC for conventional PCB cleaning are detergent and energy consumption for heating and operating the washing machine and hazardous waste treatment. Main cost factors for PCB cleaning with QW are equipment for manufacturing QW and water and energy consumption for heating and operating the washing machine. A notable cost issue is that the energy consumption and resulting cost when using $\mathrm{QW}$ is substantially lower than for conventional PCB cleaning, since the QW works best around $4-10^{\circ} \mathrm{C}$ and therefore does not require any energy for heating up the solvent used for cleaning. Figure 5 shows the breakdown of costs in percentage for "Conventional PCB cleaning" and "PCB cleaning with Qlean Water". The LCC calculations show that the cost of using QW in the Flextronics case is approximately half of the cost of conventional chemical-based cleaning (Lindahl, 2010b). For conventional cleaning, the cost for detergenst is the main cost, equal to approximately $110 \%$ of the total cost for cleaning with QW. The second largest cost is for energy, approximately equal to $40 \%$ of the total cost for cleaning with QW. For cleaning with QW in the Flextronics case, the main costs are the equipment cost (approximately 45\%), energy use (approximately 29\%) and water use (approximately 25\%).

When conducting a sensitivity analysis, it is shown that although the cost of the conventional washing would be half of today's cost, it will still be more or less $100 \%$ equal to the cost for cleaning with QW. It should be noted that Karlskrona, where Flextronics is located, has among the highest tap water price in Sweden, equal to approximately $3 € / \mathrm{m}^{3}$; more normal prices in Sweden range from 1 to $1.5 € / \mathrm{m}^{3}$. Finally, even though seawater had to be used for producing the $\mathrm{QW}$, the $\mathrm{QW}$ would be approximately $40-50 \%$ more cost efficient that conventional. It should also be noted that the "used scenario", i.e. that the QW equipment only works for 3 years, is not realistic but was selected in order to be on the "safe side" when comparing. Today, Qlean Scandinavia has QW equipment that is older than 6 years, and Flextronics' QW equipment is also rather over-dimensioned and could without any problem serve several more washing machines than the three today. If the water price and the equipment's lifetime would be more normal and realistic, the QW cleaning solutions would be even more competitive, resulting in approximately $35 \%$ of the cost compared with conventional 
cleaning. Furthermore, Flextronics has acknowledged that the PCB washing machines that use QW do not need to be as advanced as they are now, and the initial investment cost price would be reduced with the use of QW.

When analyzing the LCC results, it is important to recall that the conventional chemical-based washing method needs to be specially adapted to washing machines with features such as drying functions etc. These machines are more advanced and more expensive than those needed when using QW. The total investment cost is therefore lower when using $\mathrm{QW}$, but this has not been considered in the calculations. Chemical-based washing eventually causes siltation of the machines and will require cleaning. The cost of this has not been considered in the LCC analysis.

Finally, another cost savings with the use of QW, which, according to Flextronics is significant (much more relevant than the cost savings with the QW method), is that it offers reduced costs for the scrapping of PCBs and products with mounted PCBs in later manufacturing steps. However, this cost has been included in the LCC analysis.

\section{Concluding discussions and Future Research}

This paper presents a new way to perform industrial cleaning using QW through an industrial case of cleaning PCBs at Flextronics. The analysis of the environmental performance of using QW in industrial cleaning, compared to conventional cleaning using chemical detergents, indicates that some substantial improvements with the emissions of GHG can be seen using QW in the cleaning of PCBs. In the studied case the major improvements come from the decrease in discarded PCBs and products with mounted PCBs and the reduction of energy use in the cleaning cycles. The benefits from the exclusion of chemical detergents are harder to assess, but the manufacturing and handling of the chemicals could be potential environmental problems depending on the characteristics of the detergents. The use of QW in the cleaning of PCBs is nondependent on chemical detergents.

The LCC analysis indicates that the use of QW is less costly than the comparable conventional chemical-based cleaning method, and also implies less costly scrapping of PCBs and products with mounted PCBs. Both the environmental and economic analysis indicates positive effects from using QW. This is positive, since it is in general easier to implement a more environmentally friendly method if it is also less costly. Since cleaning is a central part of the electronic industry, this also implies that substituting conventional chemical-based cleaning of PCBs with QW could potentially result in a substantial positive environmental effect.

Finally, more research is needed from a chemical perspective to describe the chemical processes behind how the QW dissolves dirt. In addition, how QW can be applied in order to achieve the best cleaning results is an important task for future research.

\section{Acknowledgements}

The authors wish to thank all the companies involved in the SOFIQ an IQ projects for their efforts in testing the use of QW at their facilities, especially Flextronics for installing and testing the use of QW 
in their manufacturing facility. In addition, the authors wish to thank ProEnviro, the Swedish Foundation for Strategic Environmental Research (Mistra) and the Swedish Foundation for Strategic Research (SSF) for financing the SOFIQ and IQ projects.

\section{References}

1997. 5564159 Closed-loop multistage system for cleaning printed circuit boards : Treiber John H Huntington Beach, CA, United States assigned to The John Treiber Company. Journal of Cleaner Production 5, 162.

Althaus, H.J., Chudacoff, M., Hischier, R., Jungbluth, N., Osses, M., Primas, A., 2007. Life Cycle Inventories of Chemicals - Final report ecoinvent data v2.0. Swiss Centre for LCl, Empa - TSL, Dübendorf, CH.

American Chemical Society, 2008. Growing Consumer Demand For 'Greener' Cleaning Products Sparks Industry Changes. ScienceDaily.

Burkhart, M., Cassie, S., Hawelka, K., Klaiber, F., 1997. Injection Molding of High-Purity Water Components. UltraPure Water Journal.

Eastoe, J., Ellis, C., 2007. De-gassed water and surfactant-free emulsions: History, controversy, and possible applications. Advances in Colloid and Interface Science 134-135, 89-95.

Environwise, 2006. Benchmarking water use in printed circuit board (PCB) manufacturing, BG279R, Oxfordshire, UK.

Flextronics, 2012. Homepage - www.flextronics.com, Karlskrona, Sweden.

Francis, M.J., Gulati, N., Pashley, R.M., 2006. The dispersion of natural oils in de-gassed water. Journal of Colloid and Interface Science 299, 673-677.

Francis, M.J., Pashley, R.M., 2006. The effect of de-gassing on the dispersion of fine oil droplets in water. Colloids and Surfaces A: Physicochemical and Engineering Aspects 287, 36-43.

Frischknecht, R., Tuchschmid, M., Faist Emmenegger, M., Bauer, C., Dones, R., 2007. Strommix und Stromnetz. Sachbilanzen von Energiesystemen. Final report No. 6 ecoinvent data v2.0., in: Dones, R. (Ed.). Swiss Centre for LCI, PSI., Dübendorf and Villigen, $\mathrm{CH}$.

Hach Company, 2002. Water analysis handbook: drinking water, wastewater, seawater, boiler/cooling water, ultrapure water. Hach Company, Loveland, USA.

Hischier, R., Classen, M., Lehmann, M., Scharnhorst, W., 2007. Life Cycle Inventories of Electric and Electronic Equipment - Production, Use \& Disposal. Final report ecoinvent Data v2.0. Swiss Centre for LCI, Empa TSL., Duebendorf and St. Gallen, $\mathrm{CH}$.

Hur, T., Lee, J., Ryu, J., Kwon, E., 2005. Simplified LCA and matrix methods in identifying the environmental aspects of a product system. Journal of Environmental Management 75, 229-237.

ISO 3696, 1987. Water for analytical laboratory use -- Specification and test methods.

Karaman, M.E., Ninham, B.W., Pashley, R.M., 1996. Effects of Dissolved Gas on Emulsions, Emulsion Polymerization, and Surfactant Aggregation. The Journal of Physical Chemistry 100, 15503-15507.

Kemmer, F.N., 1988. The Nalco water handbook, 2nd Edition ed. McGraw-Hill.

Kikuchi, E., Kikuchi, Y., Hirao, M., 2011. Analysis of risk trade-off relationships between organic solvents and aqueous agents: case study of metal cleaning processes. Journal of Cleaner Production 19, 414-423.

Lindahl, M., 2010a. Investigation of user and customer requirements (in Swedish), LIU-IEI-R-- 10/0117-SE. Linköping University, Linköping, Sweden.

Lindahl, M., 2010b. Life Cycle Cost Analysis of the Qlean-method - A comparison with conventional cleaning of PCBs at Flextronics in Karlskrona, Report number: LIU-IEI-R-10/0124-SE (in Swedish). Linköping University, Linköping, Sweden.

Nelson, C.W., 1997. Switching to semi-aqueous cleaning of printed circuit board assemblies at Raytheon missile divisions. Journal of Cleaner Production 5, 199-201.

Osmonics Inc, 1997. Osmonics Pure Water Handbook (2nd edition). 
Pashley, R.M., Rzechowicz, M., Pashley, L.R., Francis, M.J., 2004. De-Gassed Water Is a Better Cleaning Agent. The Journal of Physical Chemistry B 109, 1231-1238.

Qlean Scandinavia AB, 2012. Homepage - www.qleanscandinavia.se, Linköping, Sweden.

Sivakumar, V., Chandrasekaran, F., Swaminathan, G., Rao, P.G., 2009. Towards cleaner degreasing method in industries: ultrasound-assisted aqueous degreasing process in leather making. Journal of Cleaner Production 17, 101-104.

Strathmann, H., 2001. Membrane separation processes: Current relevance and future opportunities. AIChE Journal 47, 1077-1087.

Sundin, E., 2004. Product and Process Design for Successful Remanufacturing, Production Systems, Department of Mechanical Engineering. Linköping University, Linköping, Sweden.

Sundin, E., Svensson, N., Lindahl, M., Björkman, M., Hammarstedt, P., 2008. Innovation Potentials of Using Solvent-free Industrial Cleaning in Swedish Manufacturing Industry, Proceedings of Sustainable Innovation 08 - Future products, technologies and industries, 13th International Conference part of the 'Towards Sustainable Product Design' series of conferences, Malmö, Sweden.

Sundin, E., Svensson, N., Lindahl, M., Hammarstedt, P., 2009. Solvent-free Industrial Cleaning of Printed Circuit Boards, in Proceedings of EcoDesign 2009, Sapporo, Japan, pp. 823-828.

Swarr, T.E., Hunkeler, D., Klopffer, W., Pesonen, H.-L., Ciroth, A., Brent, A.C., Pagan, R., 2011. Environmental Life Cycle Costing: A Code of Practice. SETAC.

Svensson, N., 2010. Environmental potential of the SOFIQ approach, Report number: LIU-IEI-R-- 10/0123-SE. Linköping University, Linköping, Sweden.

Tadahiro, O., 1995. Ultra-clean processing for ULSI. Microelectronics Journal 26, 595-619.

Wendler, B., Wolters, R., Schmidt, B., Holdinghausen, A., Prade, H., 2010. Degreasing bath care in the steel and metal working industry. Desalination 250, 1031-1033. 
Table 1. Overview of conventional method and cleaning with Qlean Water at Flextronics.

\begin{tabular}{|l|c|c|}
\hline Cleaning step & Conventional method & Cleaning with Qlean Water \\
\hline Washing & 8 minutes at $60^{\circ} \mathrm{C}$ & 2 minutes at room temperature \\
\hline Rinsing & 7 cycles with deionized water & 5 cycles with $\mathrm{HCW}$ \\
\hline Drying & 30 minutes at $65^{\circ} \mathrm{C}$ & 30 minutes at $65^{\circ} \mathrm{C}$ \\
\hline Processes & Conventional method & Cleaning with Qlean Water \\
\hline Tap water use & 1101 & 1251 \\
\hline Electricity use & $6.6 \mathrm{kWh}$ & $4.0 \mathrm{kWh}$ \\
\hline Transport, ship & 0.5 tonne-km & 0.12 tonne-km \\
\hline Transport, truck & 0.06 tonne-km & 0.02 tonne-km \\
\hline
\end{tabular}




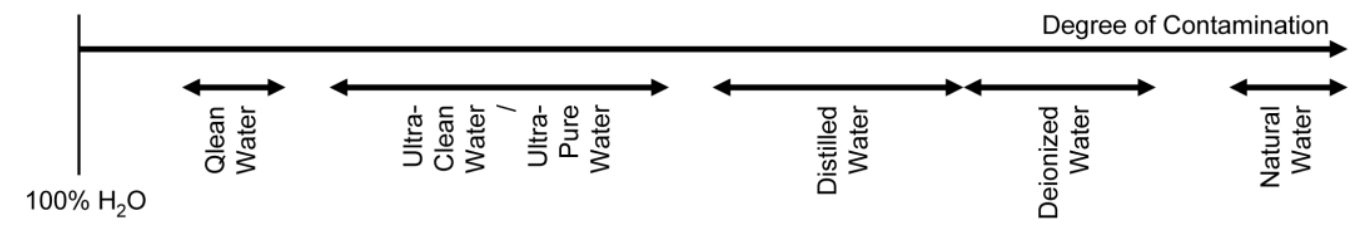

Figure 1. A description of the degree of pureness of the "water" types described in this paper. 


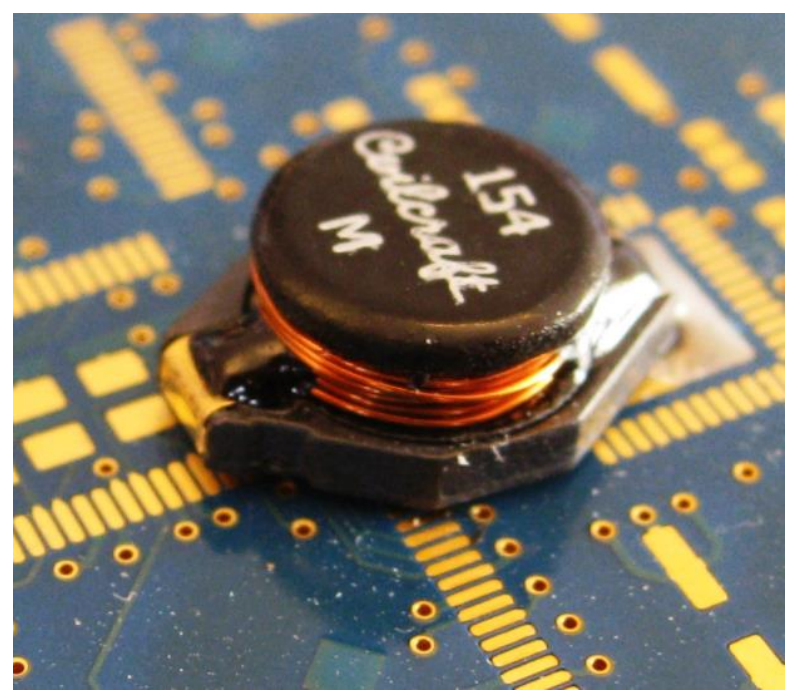

Figure 2. Printed Circuit Board component that detergents attached easily on. 


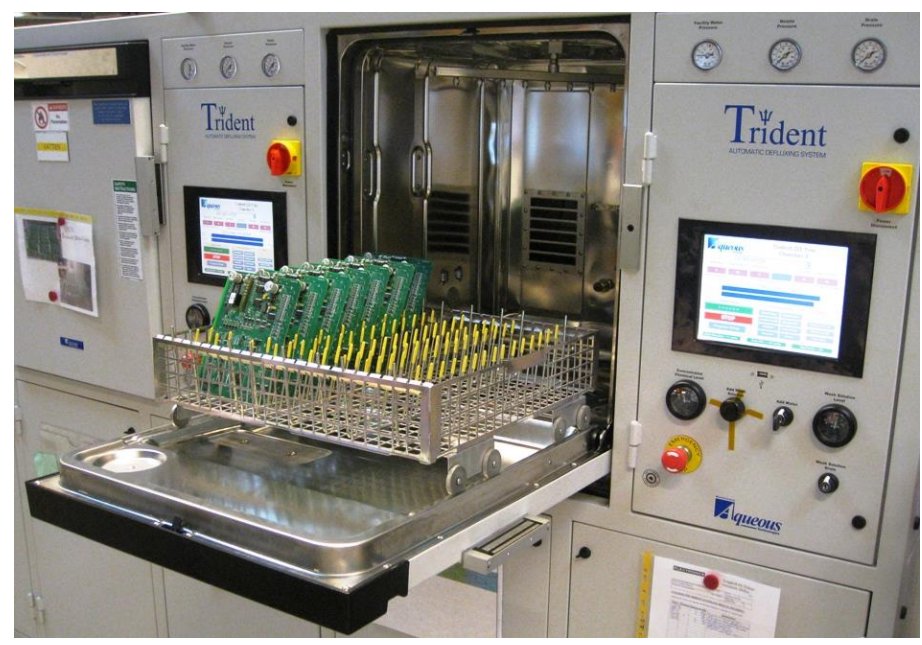

Figure 3. Flextronics' printed circuit board washing machines (Sundin et al., 2009). 

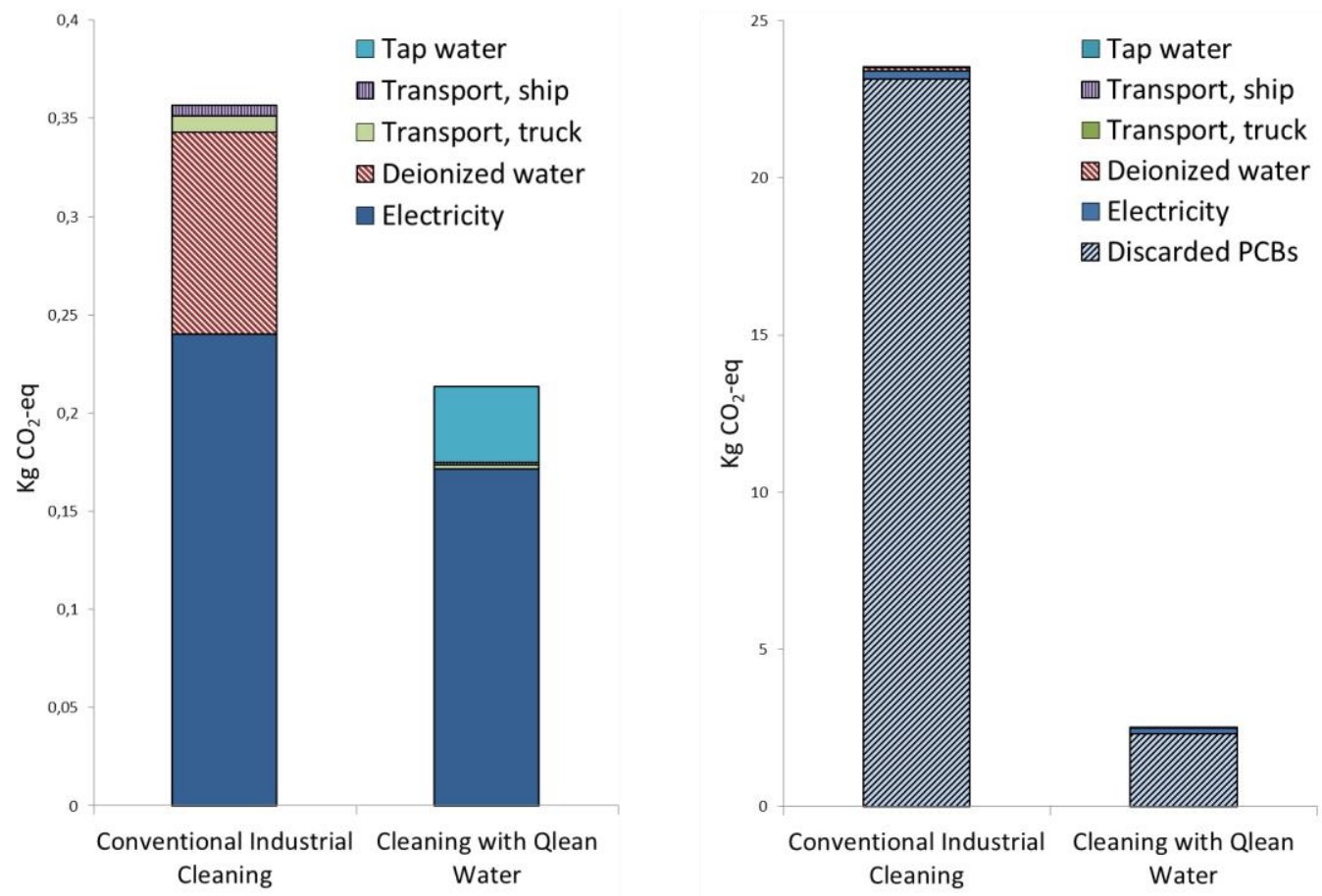

Figure 4. a) The direct GHG emissions from the cleaning process in the Flextronics case. b) climate emission from the cleaning process including emissions from discarded PCBs in the Flextronics case [Svensson, 2010]. 


\section{Conventional PCB Cleaning}

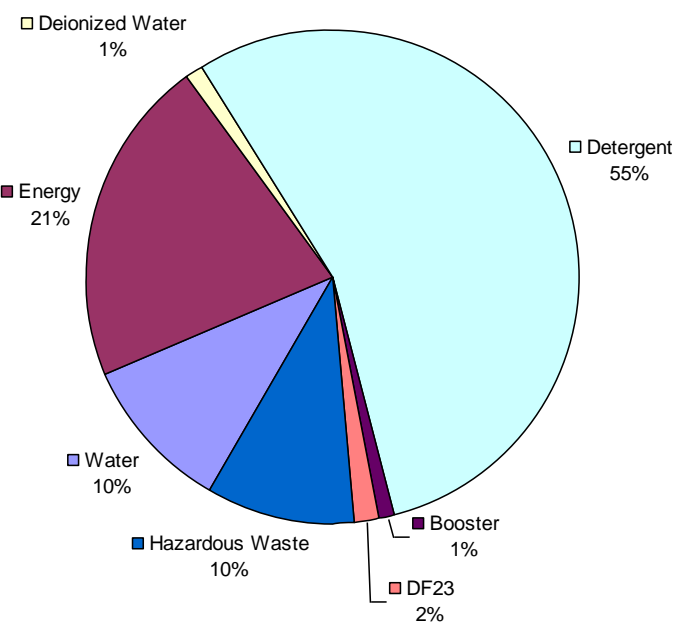

PCB Cleaning with Qlean Water

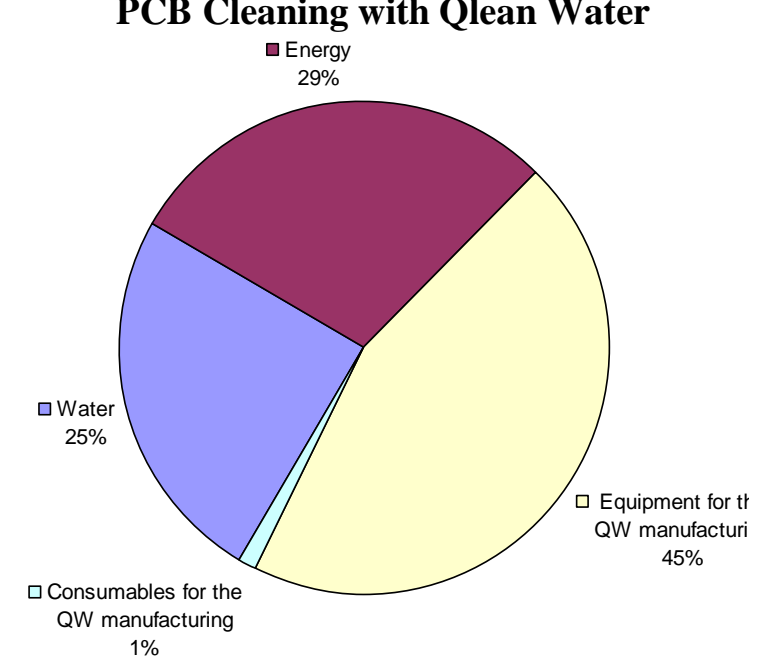

Figure 5. Breakdown of costs in percentage for "Conventional PCB cleaning" and "PCB cleaning with Qlean Water". 